\title{
Relationships between personality traits, resting serum hormones and visuomotor ability in male judokas
}

\author{
Zbigniew Obmiński ${ }^{1}$, Helena Mroczkowska ${ }^{2}$, Wiesław Tomaszewski ${ }^{3}$ \\ ${ }^{1}$ Department of Endocrinology, Institute of Sport - National Research Institute, Warsaw, Poland \\ ${ }^{2}$ Department of Psychology, Institute of Sport - National Research Institute, Warsaw, Poland \\ ${ }^{3}$ College of Physiotherapy, Wroclaw, Poland
}

Obmiński Z, Mroczkowska H, Tomaszewski W. Relationships between personality traits, resting serum hormones and visuomotor ability in male judokas. Ann Agric Environ Med. 2016; 23(1): 79-83. doi: 10.5604/12321966.1197305

\begin{abstract}
Introduction. The purpose of this research was to study the relationships between selected personality features, the speed and accuracy of visumotor ability and hormonal status in the blood of male judokas.

Materials and method. Forty-five male judokas whose body mass ranged from $66-100 \mathrm{~kg}$ were included in the study. Each one was examined once during a single annual competitive season lasting from March - October. The protocol of the study comprised five procedures carried out in the following order: (a) capillary blood sampling in the morning (07:30), (b) second capillary blood sampling directly prior to the personality examination, (c) examination of the personality traits, (d) testing of visuo-motor ability with the use of an electronic cross-shape electronic device, (e) third capillary blood sampling after the entire study. The entire study started and ended in the morning. For each subject, the three serum samples were pooled and the levels of cortisol $(C)$ and testosterone $(T)$ were determined in the serum specimen.

Results. There were significant correlations among the scores in selected personality traits, anxiety $(A)$, neuroticism (N), extraversion (E), perseveration (P), emotional reactivity (ER) and achievement motivation (AM). The $C$ level did not correlate with any variables, however, it did positively correlate with $\mathrm{E}$ and visuo-motor ability. There were inverse relationships between $E$ and $A, N, P$ and $E R$.
\end{abstract}

Conclusions. The study confirmed relationships in the androgenic status in circulation, personality traits and psycho-motor abilities.

Key words

personality, cortisol, testosterone, hormones

\section{INTRODUCTION}

In sport psychology, the majority of studies have focused on the development diagnostic tools that allow determination of the current disposition before a competition, emotions and the level of pre-competitive arousal, to find the interaction between athletic performance and psychoemotional indices, and to advise on how to optimally cope with stress. Affective states were usually investigated among athletes, together with their physiological responses to a stressful situation, while athletes' personality traits have been examined under neutral conditions, without parallel observations of bodily responses. Despite this, studies on personality traits have showed their usefulness for diagnosis and the solving of various problems among competitors. It is believed that a well personality allows one to predict in the future any affective states induced by stressful events. That assumption is based on the results of the study of competitive trait anxiety, neuroticism and extraversion, the traits which exert an influence on competitors' pre- and post-competition affective reactions [1]. In addition, data analysis [2] has shown that more than $70 \%$ of both successful and unsuccessful athletes can be indentified using general psychological measures of personality structures and mood state. Hence, the above confirms the practical usefulness of

Address for correspondence: Wiesław Tomaszewski, Institute of Sport - National Research Institute, Kościuszki 4, 50-038 Wrocław, Poland

e-mail: w.tomaszewski@wp.pl

Received: 28 April 2015; accepted: 29 July 2015 psychological studies under neutral conditions. Moreover, psychological investigations in sport comprise such facets as: gender differences in emotional reactivity under athletic stress conditions, identification of the type and sources of motivation to exercise levels of aggressiveness $[3,4,5,6,7]$, and appraisal of the adaptation to training loads using the profiles of mood state (POMS) $[8,9]$. Such examinations allow detection of the lower training tolerance, which may lead to general chronic fatigue. The determination of emotional reactivity when considered as a trait informs about the risk of a competitive hyperemotional state, which is responsible for lower levels of coping effectiveness [10]. It is worth noting that precompetitive arousal may be perceived by competitors as being favourable or unfavourable, depending on the type of emotion, which may be positive or negative. A successful coping strategy generates positively toned emotions and moods $[10,11]$, because a worse mood state and a higher anxiety state prior to contests occur more often in unsuccessful athletes. [12, 13, 14, 15]

There are relationships between the components of a general lower well-being and the hormonal status, which in athletes are modulated by excessive activity. Worse sleep quality, somatic complains and perceived fatigue are associated with higher cortisol [9] and an abnormal ratio of DHEA-S / salivary cortisol [16]. Parallel changes were found in the free testosterone to cortisol ratio and some items of the RecoveryStress Questionnaire designed for athletes (REST-Sport) after the overloading and recovery period among rugby players [17]. Some scientists are of the opinion that based on 
a comprehensive psycho-hormonal examination it is partly possible to make a prognosis about task performance and the chance of success of sports $[18,19,20,21,22,23,24,25]$, although hormones and pre-contest mood are not the only predictors of athletic outcomes, especially in sport games and combat sports. The competitive strategy tactics and style of decision-making and specific mental skills are associated with the performance of the athletes' central nervous system. That system is responsible for speed and the accuracy of information processing, intelligence, perceptions, motor learning and visuo-and/or sensory-motor coordination, memory, problem solving, and many other attributes of the human mind. All those mentally-cognitive abilities coupled with motor skills may be determined with the use of a varied battery of psychomotor tests for the assessment of simple time response, choice time response, visual searching, the dilemma of the GO/NOGO test, attention sustaining, eyehand coordination, hand-tapping speed and motor accuracy. These tests provide information regarding the functioning level of the brain-limbs pathway, which includes the sequence of stages: perception, information-processing, decisionmaking and execution [26, 27, 28, 29, 30, 31].

\section{OBJECTIVES}

In the available scientific literature little is known about whether personality traits, visuo-motor skills and blood hormones are related to each other; therefore, this study aimed to find possible relationships among these variables in senior male judokas.

\section{MATERIALS AND METHOD}

Forty-five senior male judokas, aged from 22.3 - 28.6, and with weight categories varying from $66-100 \mathrm{~kg}$, were included in the study. Each of them visited the Institute of Sport once within various terms of a single annual competitive season. The protocol of the study comprised five procedures carried out in the following order: (a) morning (07:30am) capillary blood sampling, (b) second capillary blood sampling prior to psychological study, (c) examination of personality components by use of standardized questionnaires, (d) the task of visuo-motor ability with the use of an electronic cross-shape device, (e) third capillary blood sampling after completion of the whole experiment. Examinations of personality and psycho-motor ability were carried out in the morning (starting at 09:30 and ending at 11:30. For each subject, his three serum samples were pooled and the cortisol (C) and testosterone (T) levels assayed with duplicates by means of commercial ELISA kits (DRG-.GERMANY).

Body position around 15 minutes prior to blood sampling affects the cortisol level [32]; therefore, each sample taken was conducted in a sitting position.

Personality traits were examined with the use of widelyknown, standardized questionnaires. Trait anxiety was determined using the Spielberger Trait/State Inventory, neuroticism and extraversion by means of the Eysenck Inventory, and perseverance and emotional reactivity with the use of the Zawadzki-Strelau Inventory. Achievement motivation was assayed using the experimental scale designed by H. Mroczkowska. After completion of the psychological tests, the level of visuo-motor ability (VM) was determined by means of purpose-made electronic equipment, consisting of a plate with seven bulbs placed on a horizontal and seven on a vertical arrangement. Each pair of two bulbs, one on the horizontal and one on the vertical axis, determined the coordinates for one of 49 push buttons, which have to be pressed immediately when the appropriate light stimulus appears. An electronic programme generated a series of 49 various, consecutive visual stimuli in a random, unexpected order. The frequency of stimuli was $0.83 \mathrm{~Hz}$ (50 stimuli per minute); thus, within the period of 0.83 seconds the examined subject had to identify the appropriate push button, and press it until such time that the successive stimulus appeared. Thus, the time responses were shorter than the intervals between the consecutive stimuli. Delayed responses, i.e., a time execution longer that $0.83 \mathrm{~s}$ and/or the incorrect identification of the stimulus and pushing an inappropriate button, were considered to be an incorrect response, i.e., a mistake. The performance level of the VM test was expressed as the number of good responses to the 49 stimuli. The above-test revealed such features as speed of signal visual identification, and speed of hand movement and motor coordination; however, without any differentiation between those features. All examinations were carried out in the morning (starting at 09:30 and ending at 11:30).

Data analysis was carried out using STATISTICA software, version 10 . The study protocol was approved by the Ethical Committee at the Institute of Sport, in accordance with the Helsinki Declaration of 1975.

\section{RESULTS}

Means and SD values of the variables are shown in Table 1. Linear correlation coefficients are presented in Table 2.

Table 1. Scores in personality traits, serum hormone levels ( $\mathrm{nmol} / \mathrm{L}$ ) and number of correct responses to the 49 stimuli emitted during visuomotor test

\begin{tabular}{lccccccccc}
\hline Var. & An & N & E & P & ER & AM & C & T & VM \\
\hline $\mathrm{X}$ & 38.2 & 27.6 & 29.7 & 16.8 & 14.3 & 36.1 & 345 & 25.7 & 39.3 \\
\pm SD & \pm 8.7 & \pm 13.1 & \pm 8.2 & \pm 5.6 & \pm 7.6 & \pm 6.0 & \pm 77 & \pm 6.2 & \pm 10.3 \\
\hline Min & 27 & 7 & 13 & 8 & 9 & 24 & 199 & 15.8 & 29 \\
\hline Max & 55 & 41 & 32 & 21 & 21 & 39 & 436 & 37.4 & 44
\end{tabular}

An - anxiety; N - neuroticism; E - extraversion; P - perseveration; ER - emotional reactivity; AM - motivation achievement; C,T - blood cortisol, testosterone; VM - performance in the visuo-motor test

Table 2. Matrix of correlation coefficients between psychological variables in male judokas

\begin{tabular}{|c|c|c|c|c|c|c|c|c|c|}
\hline Var. & An & $\mathrm{N}$ & E & $P$ & ER & AM & C & $\mathrm{T}$ & VM \\
\hline An & 1 & 0.59 & -0.45 & 0.59 & 0.41 & -0.32 & 0.27 & -0.31 & -0.08 \\
\hline$N$ & & 1 & -0.27 & 0.39 & 0.77 & -0.39 & 0.26 & -0.32 & 0.01 \\
\hline$E$ & & & 1 & -0.45 & -0.49 & 0.30 & -0.16 & 0.35 & 0.15 \\
\hline P & & & & 1 & 0.69 & -0.25 & -0.09 & -0.41 & -0.05 \\
\hline ER & & & & & 1 & -0.30 & 0.19 & -0.39 & 0.01 \\
\hline $\mathrm{MA}$ & & & & & & 1 & -0.16 & 0.27 & 0.04 \\
\hline C & & & & & & & & 0.06 & -0.08 \\
\hline $\mathrm{T}$ & & & & & & & & & 0.31 \\
\hline VM & & & & & & & & & 1 \\
\hline
\end{tabular}


There were significant correlations among the scores in selected personality traits, neuroticism, extraversion, perseveration, emotional reactivity and achievement motivation (Tab. 2). Performance of the psychomotor test positively correlated with the serum testosterone level. Unexpectedly, the serum cortisol level did not correlate either with the personality traits or with the performance level of the psychomotor test. The testosterone level positively correlated with the scores of psychometric ability and extraversion, but negatively with anxiety, neuroticism, perseveration and emotional reactivity. There were no significant relationships between the performance of the visuo-motor test and body mass $(r=-0.17)$.

\section{DISCUSSION}

Although psychological states (moods) fluctuate significantly depending on external and internal circumstances, psychologists are of the opinion that the personality traits are relatively stable parameters, which are dependent partly on early life events, social environment and genetic factors [33, $34,35,36]$. The presented study shows wide ranges (min-max) of all six personality indices, and a relative high one between the subject variability of these indices (compare the values of $\left.\mathrm{CV} \%=(\text { mean } / \mathrm{SD})^{*} 100 \%\right)$. It is worth stressing that there were negative correlation between the so-called 'positive' and 'negative' traits. It is assumed that a positive trait in sport is extraversion, because a high score on $\mathrm{E}$ favours correct social, between-participant relationships, and coach-athlete cooperation. That feature is especially in demand in team sports, but plays a lesser role in individual and/or endurance sports, or in non-athletes [37,38]. Neuroticism, perseverance and emotional reactivity, as well as a very high anxiety trait, are negative features, which rather impede cooperation. High scores on trait anxiety and emotional reactivity may induce higher pre-competitive fear of failure. It is assumed that higher scores on neuroticism $(\mathrm{N})$ and perseverance $(\mathrm{P})$ may favour mentally tough behaviours (MTB). Although there is a lack of evidence-based findings that MTB is related to high $\mathrm{N}$ and $\mathrm{P}$, it was found that higher MTB occurred in athletes who were sensitive to punishment but insensitive to reward [39]. The level of neuroticism allows one to predict the intensity of precompetitive stress. An electro-dermal study conducted in Taekwondo competitors showed that $\mathrm{N}$ explains precompetitive arousal [40]. That finding explains the significant positive correlation between neuroticism and trait anxiety in the current study.

There are a number of studies on the levels of cognitive functions among athletes practicing combat sports. Most often determined are simple and choice time response recorded at rest, and following different physical exertions. These studies are important, especially in those sports which require speed and the correct recognition of a situation, appropriate decision-making and decision-execution. These demands occur in racket-, combat sports and sports games. In general, task-structures in various sports impose the development of appropriate psychomotor abilities. Moreover, practicing these sports (tennis) as recreation helps one to maintain a better psychomotor ability at a late age. For instance, car drivers who habitually played tennis demonstrated better simple, choice time responses, movement time and time response under single- and dual-task conditions than those who did not [41].
Interestingly, the performance of coincidence-anticipation timing accuracy (time reaction and errors) tasks with various velocities (low, medium and fast) differed in tennis, table tennis, and badminton players, and were adapted to the specific task structures of those sports [42]. A similar study showed that junior tennis players displayed fewer errors, while table tennis players showed lower time responses [43]. Table tennis players had a shorter summarized visual simple time response (to the subsequent emitted 80 stimuli) than the controls [44].

A comparison of the results of all the above-quoted studies with the presented study is impossible because of the different utilized tools used for the testing of visuo-motor abilities. The most frequent examination of psycho-motor skills include simple and choice time reaction. A study on wrestlers showed that the performance of choice time responses is dependent on motivation levels [45]. The absence of a similar phenomenon in the current study may be explained by the other psychometric test and psychological questionnaire used for estimation of the motivation.

The cross-shape devices used in this study are utilized in Poland during car driving license tests. Among judokas this device had been used previously during a competition, [29] or during the pre- and post-judo training period [31]. In that study, elite senior judokas scored a somewhat lower number of correct responses before preparatory training $(40.7 \pm 4.9)$ when compared to that after the training (43.8 \pm 3.1$)$ [31]. The use of other electronic devices in judokas revealed the differences in psychomotor skills, which were related to the level of the sport class [30]. The presented study did not show relationships between body mass and visuo-motor skill, while Skurvydas [46] reported a longer time response in heavier subjects. Probably practicing judo at a competitive level for a dozen or so years blunted the effect of body mass.

The examined serum cortisol and testosterone levels are not stable over the day. Apart from the changes which occur according to the diurnal rhythms, both hormones demonstrate oscillations (rises and falls) due to two concurrent processes: metabolism and episodic secretions. The frequency and amplitude changes in the concentrations are recognized due to the deconvolution analysis carried out among humans for serum cortisol $[47,48]$ and testosterone. $[49,50]$ Hence, because of the hormonal fluctuations, the more valuable relationships between serum and psychometric variables required an aggregating of the hormonal data to yield better relationships [51, 52]. That is why in this experiment, the hormonal data obtained from the analysis of pooled serum samples were taken into consideration. The relationships between serum testosterone levels and performance in the visuo-motor test may suggest the beneficial effect of androgenic status on cognitive function in young adults who exercise, but this hypothesis needs further investigation, because to-date that effect has been reported only in aging men [53] and women [54] suffering from polycystic ovarian syndrome. The serum cortisol level is considered as a marker of stress, since it rises in response to a challenging situation. However, the relationship between state anxiety and circulating cortisol is not always close, as reported by A. Salvador A who examined judo competitors prior to a competition; on the other hand, the higher cortisol and testosterone levels were associated with a higher motivation to win [55]. That study provides evidence that precompetitive arousal may trigger concurrently positive emotions/higher 
motivation along with excitation of the hormonal system, of the so-called stress hormones. In the presented study, achievement motivation was not related to the serum cortisol level, but was slightly related to that of testosterone. Taking into consider the results of the investigations by Salvador [55], one would expect the stronger correlation to be prior to a competition.

Summing-up the single testing test of selected personality traits provides information on the level of mental toughness and those psychological attributes which are responsible for the effective functioning in a social environment. Moreover, these studies help one to understand and to predict the type of behaviour in stressful situations. The combination of these observations with a determination of visuomotor ability and the current hormonal status provides comprehensive information about precompetitive psychophysical disposition.

\section{CONCLUSIONS}

1. Aggregated data of the hormonal status in blood showed significant relationships between current testosterone level and visuo-motor ability.

2. Achievement motivation and testosterone were inversely related to anxiety, neuroticism, emotional reactivity and perseveration, but positively to extraversion.

3. At the rest condition, in male athletes, the higher blood testosterone is associated with better visuo-motor skills.

\section{REFERENCES}

1. Cerin E, Barnett A. Predictors of pre- and post-competition affective states in male martial artists: a multilevel interactional approach. Scand J Med Sci Sports. 2011; 21(1): 137-150.

2. Reglin JS. Psychological factors in sport performance: The Mental Health Model revisited. Sports Med. 2001; 31(12): 875-890.

3. Mroczkowska H. Conformity with the pattern of maleness and cognitive-motivational determinants of aspirations for success in woman. Biol Sport. 2007; 24(3); 275-284.

4. Mroczkowska H. Cultural gender schemes vs. emotional parameters of men and women functioning in professional athletics. Biol Sport. 2005; 22(3): 271-279.

5. Mroczkowska H, Kownacka, Obmiński Z. Study of the indicators of social aggressiveness in competitors practicing combat sports. Pol J Sport Tourism. 2008; 15(4): 158-161.

6. Obmiński Z, Mroczkowska H, Stupnicki R. Pre-exercise cortisol and testosterone levels in relation to selected psycho-emotional variables in male and female junior rowers. Biol Sport. 1995; 12: 43-48.

7. Obmiński Z, Mroczkowska H, Kownacka I. State anxiety and perception of fatigue following rowing regatta. Pol J Sports Med 2010; 26: 260-266.

8. Coutts AJ, Reaburn P, Monitoring changes in rugby league players' perceived stress and recovery during intensified training. Pecept Mot Skills. 2008; 106(3): 904-916.

9. Jürimäe J, Mäestu J, Purge P, Jürimäe J. Changes in stress and recovery after heavy training in rowers. J Sci Med Sports 2004; 7(3): 335-339.

10. Nicholls AR, Jones CR, Polman RC, Borkoles E, Acute sport-related stressors, coping, and emotion among professional rugby union players during training and matches. Scand J Sports Med. 2009; 19(1): 113-120.

11. Nicholls AR, Hemming SB, Clough PJ. Stress appraisals, emotions, and coping among international adolescents golfers. Scand J Med Sci Sports. 2010; 20(2): 346-355.

12. Chapman C, Lane AM, Brierley JH, Terry PC. Anxiety, self-confidence and performance in Tae-Kwon-Do. Percept Mot Skills 1997; 85(3): $1275-1278$.

13. Pieter W, Wong RSK, Ampongan C, Mood and experience as correlates of performance in young Filipino Taekwondo athletes. Acta Kinesiologiae Universitatis Tartuensis 2006; 11: 64-72.
14. Wong RSK, Thung JS, Pieter W. Mood and performance in young Malaysian karateka. J Sports Sci Med. 2006 (CSSI): 54-59.

15. Cheng WN, Hardy L, Woodman T. Predictive validity of a threedimensional model of performance anxiety in the context of tae-kwondo. J Sport Exerc Psychol. 2011; 33(1): 40-53.

16. Obmiński Z, Zdanowicz R, Elżbieta Grądzka E. Relationships between rating of perceived exertion and blood indices during training sessions of various intensity in female taekwondo players. J Combat Sports Martial Arts 2013; 2(2): 125-129.

17. Coutts AJ, Wallace LK, Slattery KM. Monitoring changes in performance, physiology, and psychology during overreaching and recovery in triathletes. Int J Sports Med. 2007; 28: 125-134.

18. Raglin JS, Morgan WP, Luchsinger AE. Mood and self motivation in successful and unsuccessful female rowers. Med Sci Sports Exerc. 1990; 22(6): 849-853.

19. Cockerill IM, Nevill AM, Lyons N. Modeling mood states in athletic performance. J Sports Sci. 1991; 9(2): 205-212.

20. Raglin JS, Morris MJ. Pre-competition anxiety in women volleyball players: a test of ZOF theory in a team sport. Br J Sports Med. 1994; 28(1): 47-51.

21. Iso-Akola SE. Intrapersonal and interpersonal factors in athletic performance. Scand J Med Sports. 1995; 5(4): 191-199.

22. Pedersen DM, Manning CL. A cross-sport athletic performance rating scale. Percept Motor Skills. 2003; 97(3): 1128-1132.

23. Weiss MR, Amorose AJ, Wilko AM. Coaching behaviors, motivational climate, and psychosocial outcomes among female adolescent athletes. Pediatric Exerc Sci. 2009; 21(4): 475-492.

24. Jones MT, Mathews TD, Murray M, van Raalte J, Jensen EE. Psychological correlates of performance in female athletes during a 12 -week of-season strength and conditional program. J. Strength Cond. Res. 2010; 24(3): 619-628.

25. Salvador A, Suay F, González-Bono E, Serrano MA. Anticipatory cortisol, testosterone and psychological responses to judo competition in young men. Psychoneuroendocrinology. 2003; 28(3): 364-375.

26. Luft CD, Takase E, Darby D. Heart rate variability and cognitive function; effects of physical effort. Biol Psychol. 2009; 82(2): 164-168.

27. Del Parcio C, Babiloni C, Bertollo M, Marzano N, Iacoboni M, Infarinato $\mathrm{F}$, et al. Visuo-attentional and sensorimotor alfa rhythms are related to visuo-motor performance in athletes. Hum Brain Mapp. 2009; 30(11): 3527-3540.

28. Le Runigo C, Benguigi N, Bardy B. Visuo-motor delay, informationmovement coupling, and expertise in ball sports. J. Sports Sci. 2010; 28(3): 327-337.

29. Sterkowicz S, Blecharz J, Lech G. Differentiation between high class judoists in terms of indices of experience, physical development, psychomotor fitness and their activities during competitions. J Hum Kinetics. 2000; 4: 93-10.

30. Supiński J, Obmiński Z, Kubacki R, Kosa J, Moska W. Usefulness of the psychomotor tests for distinguishing the skill levels among older and younger judo athletes. Archives Budo 2014; 10: 315-322.

31. Obmiński Z, Litwiniuk A, Staniak Z, Zdanowicz R, Zhu Weimo. Intensive specific maximal judo drills improve psycho-motor ability but may impair hand grip isometric strength. IDO MOVEMENT FOR CULTURE. J Martial Arts Anthropol. 2015; 15(2): 52-58.

32. Hennig J, Friebe J, Ryl I, Krämer B, Böttcher J, Netter P. Upright posture influences salivary cortisol. Psychoneuroendocrinology. 2000; 25(1):69-83.

33. Knafo-Noam A, Uzefovsky F, Israel S, Davidov M, Zahn-Waxler C. The pro-social personality and its facets: genetic and environmental architecture of mother-reported behavior of 7-year-old twins. Front Psychol. 2015 Feb 13;6:112. eCollection 2015.

34. Van den Berg SM, de Moor MH, McGue M, Pettersson E, Terracciano A, Verweij KJ, et al. Harmonization of Neuroticism and Extraversion phenotypes across inventories and cohorts in the Genetics of Personality Consortium: an application of Item Response Theory. Behav Genet. 2014 Jul; 44(4): 295-313.

35. Luciano M, Huffman JE, Arias-Vásquez A, Vinkhuyzen AA, Middeldorp $\mathrm{CM}$, Giegling I, et al. Genome-wide association uncovers shared genetic effects among personality traits and mood states. Am J Med Genet B Neuropsychiatr Genet. 2012; 159B(6): 684-695.

36. Vinkhuyzen AA, Pedersen NL, Yang J, Lee SH, Magnusson PK, Iacono WG, et al. Common SNPs explain some of the variation in the personality dimensions of neuroticism and extraversion. Transl Psychiatry. 2012 Apr. 17; 2: e102.

37. Eagleton JR, McKelvie SJ, de Man A. Extraversion and neuroticism in team sport participants, individual sport participants, and nonparticipants. Percept Mot Skills. 2007; 105(1): 265-275. 
38. Malinauskas R, Dumciene A, Mamkus G, Venckunas T. Personality traits and exercise capacity in male athletes and non-athletes. Percept Mot Skills. 2014; 118(1): 145-161.

39. Chrapusta A, Pąchalska M. Evaluation of differences in health-related quality of life during the treatment of post-burn scars in pre-school and school children. Ann Agric Environ Med. 2014; 21(4): 861-865.

40. Binboga E, Guven S, Catıkkaș F, Bayazıt O, Tok S. Psychophysiologica responses to competition and the big five personality traits. J Hum Kinet. 2012; 33: 187-194.

41. Marmeleira J, Melo F, Tlemcani M, Fernandes J. Tennis playing is related to psychomotor speed in older drivers. Percept Mot Skills. 2013; 117(2): 457-469.

42. Akpinar S, Devrilmez E, Kirazci S. Coincidence-anticipation timing requirements are different in racket sports. Percept Mot Skills. 2012 Oct; 115(2): 581-93

43. Ak E, Koçak S. Coincidence-anticipation timing and reaction time in youth tennis and table tennis players. Percept Mot Skills. 2010 Jun; 110(3 Pt 1): 879-87.

44. Bhabhor MK, Vidja K, Bhanderi P, Dodhia S, Kathrotia R, Joshi V. A comparative study of visual reaction time in table tennis players and healthy controls. Indian J Physiol Pharmacol. 2013 Oct-Dec; 57(4): 439-442.

45. Korobeynikov G, Mazmanian K, Korobeynikova L, Jagiello W. Diagnostics of psychophysiological states and motivation in elite athletes. Bratisl Lek Listy. 2011; 112(11): 637-643.

46. Skurvydas A, Gutnik B, Zuoza AK, Nash D, Zuoziene IJ, Mickeviciene D. Relationship between simple reaction time and body mass index. Homo. 2009; 60(1): 77-85.
47. Trifonova ST, Gantenbein M, Turner JD, Muller CP. The use of saliva for assessment of cortisol pulsatile secretion by deconvolution analysis. Psychoneuroendocrinology. 2013; 38(7): 1090-1101.

48. Faghih RT, Dahleh MA, Adler GK, Klerman EB, Brown EN. Deconvolution of serum cortisol levels by using compressed sensing. PLoS One. 2014 Jan 28; 9(1): e85204.

49. Veldhuis JD, Liu PY, Takahashi PY, Keenan DM. Dynamic testosterone responses to near-physiological LH pulses are determined by the time pattern of prior intravenous LH infusion. Am J Physiol Endocrinol Metab. 2012; 15; 303(6): E720-728.

50. Mattsson P, Medvedev A. Modeling of testosterone regulation by pulsemodulated feedback. Adv Exp Med Biol. 2015; 823: 23-40.

51. Pruessner JC, Gaab J, Hellhammer DH, Lintz D, Schommer N, Kirschbaum C. Increasing correlations between personality traits and cortisol stress responses obtained by data aggregation. Psychoneuroendocrinology. 1997; 22(8): 615-625.

52. Li I, Chiou HH, Shen PS. Correlations between cortisol level and internalizing disposition of young children are increased by selecting optimal sampling times and aggregating data. Dev Psychobiol. 2007; 49(6): 633-639.

53. Van Strien JW, Weber RF, Burdorf A, Bangma C. Higher free testosterone level is associated with faster visual processing and more flanker interference in older men. Psychoneuroendocrinology. 2009; 34(4): 546-554.

54. Barry JA, Parekh HS, Hardiman PJ. Visual-spatial cognition in women with polycystic ovarian syndrome: the role of androgens. Hum Reprod. 2013 Oct; 28(10): 2832-2837.

55. Salvador A, Suay F, González-Bono E, Serrano MA. Anticipatory cortisol, testosterone and psychological responses to judo competition in young men. Psychoneuroendocrinology. 2003; 28(3): 364-375. 